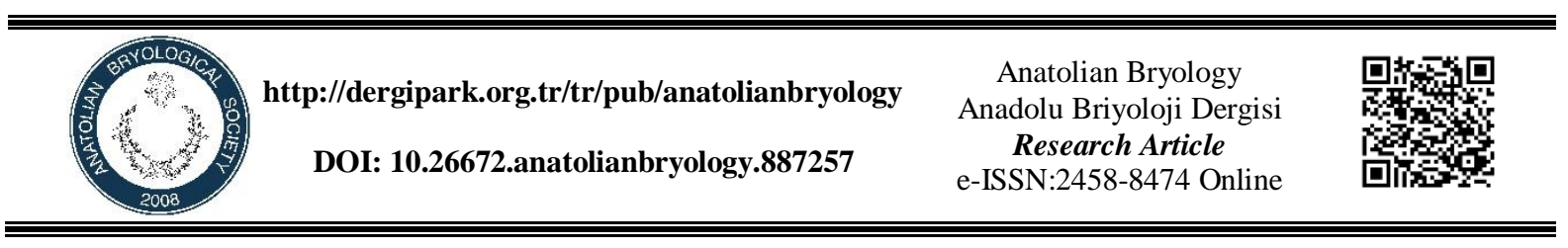

Acarlar Gölü Longoz Ormanı (Sakarya) Karayosunu Florası

\author{
Serhat URSAVAŞ ${ }^{1 *}$ (D), Tamer KEÇELI' ${ }^{2}$ iD

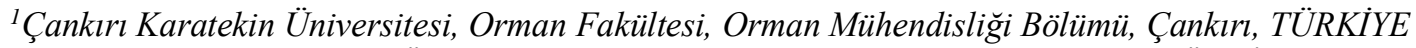 \\ ${ }^{2}$ Çankırı Karatekin Üniversitesi, Fen Fakültesi, Biyoloji Bölümü, Çankırı, TÜRKIYE
}

\begin{abstract}
Received: 26 February $2021 \quad$ Revised: 20 March 2021 $\quad$ Accepted: 22 March 2021
$\ddot{O} \mathbf{z}$

Bu çalışmada, 2016-2017 yıllarının farklı vejetasyon dönemlerinde Acarlar Gölü Longoz Ormanlarında yapılan arazi çalışmaları sonucunda 25 istasyondan toplam 248 karayosunu örneği toplanmıştır. Toplanan örneklerin teşhis çalışmaları yapılmış olup 23 familya, 58 cins ve bu cinslere ait toplam 93 takson tespit edilmiştir. Bu taksonlardan; 29'u Sakarya ili briyofit florası için, 6 takson ise A2 karesi için yeni kayıtır. Ayrıca, bu bölgeden kaydı verilen; Atrichum crispum, Pseudephemerum nitidum ve Dicranella staphylina Türkiye briyofit florası için önemli taksonlardandır.
\end{abstract}

Anahtar kelimeler: Subasar Ormanı, Karayosunu, Flora, Göl, Sakarya, Türkiye.

\title{
The Moss Flora of Acarlar Lake Longoz Forest (Sakarya)
}

\begin{abstract}
In this study, a total of 248 moss samples were collected from 25 stations as a result of the field studies carried out in the Acarlar Lake Longoz Forests during the different vegetation periods of 2016 and 2017. According to the identification studies of the collected samples, 23 families, 58 genera and a total of 93 taxa belonging to these genera were determined. Of the determined taxa, 29 are new records for Sakarya province bryophyte flora and 6 taxa are new records for A2 square. Also, registered from this region; Atrichum crispum, Pseudephemerum nitidum and Dicranella staphylina are also important species for bryophyte flora of Turkey.
\end{abstract}

Keywords: Flooded Forest, Mosses, Flora, Lake, Sakarya, Turkey.

\footnotetext{
* Corresponding author: serhatursavas@gmail.com

(C) 2021 All rights reserved / Tüm hakları saklıdır.

To cite this article: Ursavaş S. Keçeli T. 2021. Acarlar Gölü Longoz Ormanı (Sakarya) Karayosunu Florası. Anatolian Bryology. 7:1, 23-32. 


\section{Giriş}

Longoz orman1, yılın belli dönemlerinde veya y1l boyunca taban suyunun yüksek olmasına bağlı olarak bataklık ve göllerden oluşan ormandır (Anonim, 2004). Yüksekliği yaklaşık 15-20 m olan subasar orman bitki topluluğu, sık sayılabilecek bir yüksek orman formasyonundadır. $\mathrm{Bu}$ orman toplulukları Türkiye'nin kuzeybatısı (Karadeniz'in güneybatı sahillerinde) (Türkiye'nin kuzeybatısı ve Bulgaristan'daki birkaç su basan vadide) görülen çok nadir ve önemli habitatlar olup, her iki ülkede de ortak olarak 'longoz' seklinde adlandirılmaktadırlar (URL1, 2006; Baykal, 2006).

Bu tip doğal alanların, sahip oldukları biyolojik çeşitlilik, doğal-kültürel, tarihi ve peyzaj kaynak değerlerin sadece bugün için değil, aynı zamanda gelecek nesillerin de bu değerlerden yararlanabilmeleri amaciyla korunmaları gerekmektedir. Bu kapsamda, taşıdıkları kaynak değerlerinden dolayı önemli görülen doğa alanları, ulusal yasalar ve uluslararası sözleşmelerle koruma altına alınmaktadır (Baykal, 2006).

Wenger ve arkadaşları (1990), Avrupa'daki taşkın yataklarından oluşan orman ekosistemlerinde oluşan azalmalara bağlı olarak, bu ormanın yararlı yapılarını ve bitki çeşitliliğini karakterize etmek için yapılan çalışmaların önemini ve önceliğini vurgulamaktadır. Ayrıca, bir biyoçeşitlilik deposu olarak ormanlık sulak alanlar, briyofit biyoçeşitliliğini tanımlayan en önemli bileșendir (Schuck ve ark., 1994; Kavgaci ve ark., 2007; Işın ve Ursavaş, 2018; Alataş ve ark., 2019a; 2019b).

Acarlar Gölü Longoz Ormanı, ekosistem çeşitliliği açısından önemli bir alan olmasına rağmen alanda şu ana kadar karayosunu florası ile ilgili herhangi bir çalışma yapılmamıştır. Bu çalışmanın amacı, daha önceden $\mathrm{Bu}$ çalışmanın amacı, daha önceden karayosunu çeşitliliği açısından çalışılmamış bu alanın karayosunu zenginliğini ortaya çıkartmaktır.

\subsection{Araştırma alanının tanıtımı}

Henderson (1961) kareleme sistemine göre ise A2 karesinde yer alan Acarlar Gölü Longoz Ormanları,
Sakarya ilinin Karasu ve Kaynarca ilçeleri sınırlarında yer almaktadır (Şekil 1). Çalışılan istasyonlarda en düşük rakım $2 \mathrm{~m}$, en yüksek rakım ise $50 \mathrm{~m}$ 'dir. Longoz ormanı sahası kıyıya paralel uzanmakta, Karadeniz kıyı çizgisinden yaklaşık 1.5 $\mathrm{km}$ içeride ve $7.5 \mathrm{~km}$ uzunluğundadır. Sulak alanda en geniş yer $1250 \mathrm{~m}$, en dar yer ise $250 \mathrm{~m}$ dir (Gönençgil, 2008; Sarığlu ve Keçeli, 2018).

Acarlar gölü, Sakarya nehrinin Karadeniz'e döküldüğü kesimden yaklaşık $6 \mathrm{~km}$ batıda, Denizköy'ü güneybatısındaki Üçoluk köyüne bağlayan yol üzerindeki Gölköprü'den itibaren başlamaktadır. Buradan itibaren Karadeniz kıyı çizgisinden ortalama $1.5 \mathrm{~km}$ içeride ve kıyıya paralel olarak, batıya doğru dar ve uzunlamasına yaklaşık 7,5 km devam etmektedir (Baykal, 2006).

Acarlar gölünün doğusu Karasu ilçesi içinde yer almaktadır. Göl alanının çevresinde Karasu'ya ait 5 adet köy bulunmaktadır. Karasu ilçesine bağlı olarak gölün doğusunda Deniz köy, güneydoğusunda Kara müezzinler ve Üçoluk köyleri, güneyinde Taslı geçit köyü, kuzeyinde de kıyıya yakın kesimde Cami tepe köyü bulunmaktadır (Baykal, 2006).

Acarlar Gölü'nün batısı ise Kaynarca ilçesinin sınırlarında bulunur. Göl alanının çevresinde Kaynarca'ya ait 3 adet köy bulunmaktadır. Kaynarca ilçesine bağlı olarak güneybatısında Turnalı köyü, güneyinde Büyükyanık köyü ve batısında Birlik köyü bulunmaktadır. Acarlar Gölü ve yakın çevresinin sınırı bu 8 köye girmektedir. Asıl göl alanının en dar yeri $250 \mathrm{~m}$ civarında olup, en geniş yeri kuzeybatıya doğru sonlandığı kesimlerde yaklaşık $1250 \mathrm{~m}$ civarındadır. Göl alanı $23.231 \mathrm{~km}^{2}$ ' dir. Gölün derinliği yazın 1 m'ye kadar düşüp, kısın yaklaşık 5 m'ye çıkmaktadır. Acarlar Gölünü birçok lagün veya sulak alandan ayıran ve ülkemizde çok az sulak alanda karşımıza çıkan özelliği göl tabanının tamamen geçilmesi zor, yoğun bir orman dokusu ile kaplı olmasıdır. Göl tabanı longoz su basar ormanı ile yoğun bir şekilde kaplanmıştır (Baykal, 2006). 


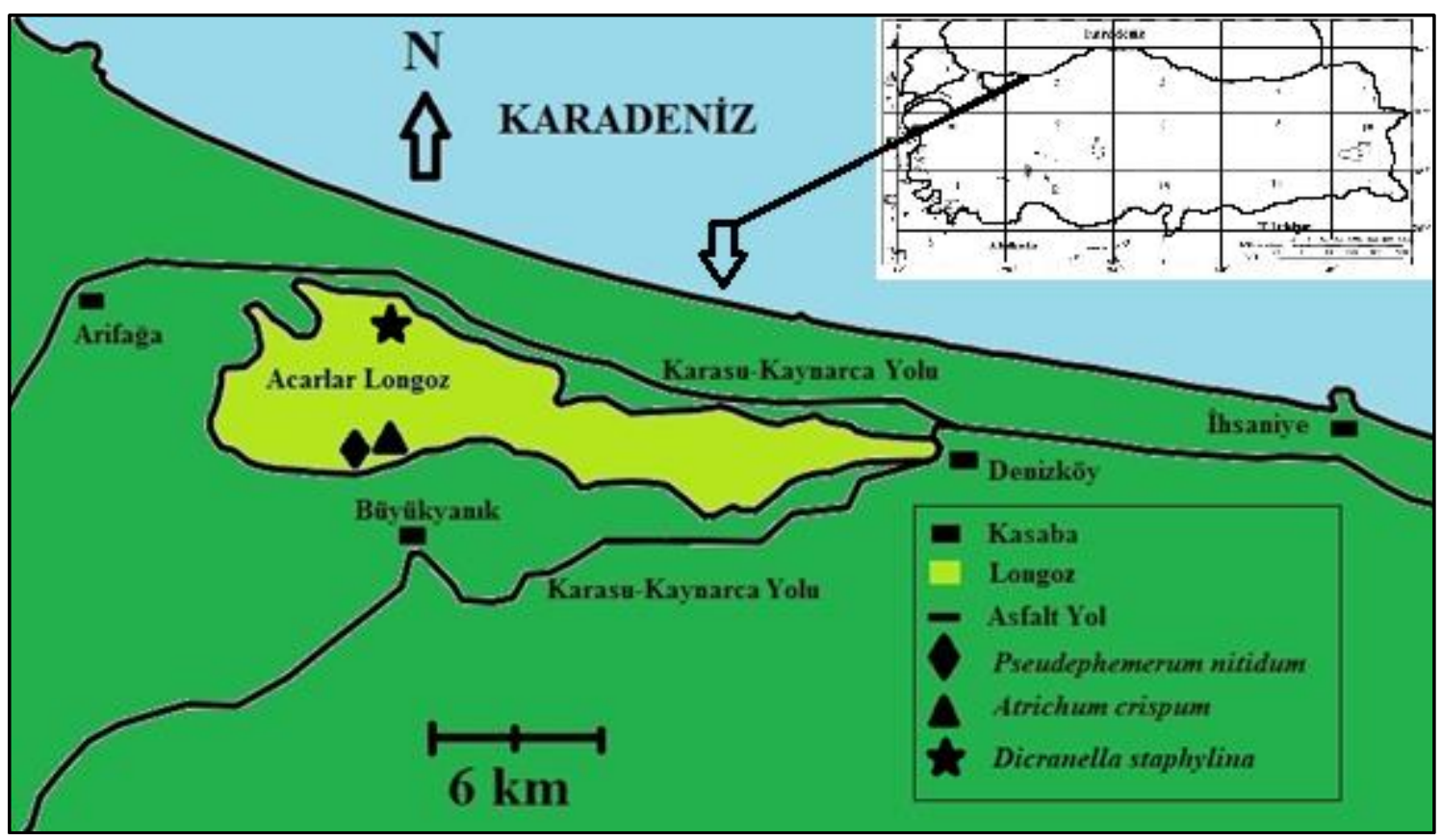

Şekil 1. Acarlar gölü Longoz ormanı sınırları ve alandan tespit edilen önemli karayosunu taksonlarının lokaliteleri.

\section{Materyal ve Yöntem}

Bu çalışmanın materyalini, Acarlar Gölü Longoz Ormanı'nın farklı lokalitelerinden toplanmış olan karayosunu örnekleri oluşturmaktadır. Sakarya Acarlar Longoz Ormanı sınırları içerisindeki farklı mevkilerden, $2-50 \mathrm{~m}$ yükseklikler arasında 25 istasyondan toplam 248 bitki örneği toplanmıştır. Toplanan örneklerin teşhisleri yapıldıktan sonra, Çankırı Karatekin Üniversitesi, Orman Fakültesi, Orman Botaniği Ana Bilim Dalında URSAVAŞ'a ait kişisel herbaryumda örnekler muhafaza edilmektedir.

Karayosunu örneklerinin teşhislerinde; Leica EZ4 HD Stereo mikroskop ve Olympus BX50 Işı mikroskobunda incelenerek temel flora kitaplarından yararlanılarak teşhisleri yapılmıştır (Smith, 1980, 2004; Pedrotti, 2001, 2006; Greven, 2003; Heyn ve Herrnstadt, 2004).

Teşhisleri yapılan taksonların Sakarya ili için yeni olup olmadıklarının tespitinde Ezer, 2017; Can Gözcü, ve ark., 2018, 2019; Ursavaş ve Işın, 2019 çalışmaları ile türlerin güncel isimlerinin belirlenmesinde ise Hodgetts ve Lockhart, 2020 çalışmalarından yararlanılmıştır.

\section{Bulgular}

\subsection{Kisaltmalar}

Listede, Sakarya ili için ilk kez kaydı verilen taksonlar tek y1ldız (*), A2 karesi için yeni olan taksonlar iki yıldız (**) ve Türkiye briyofit florası için nadir ve hassas olabilecek önemli bazı taksonlar ise siyah üçgen ( $(\boldsymbol{\Delta})$ işareti konulmuştur.

\section{2 İstasyon noktaları}

1) Sakarya Acarlar Longoz girişi Denizköy Mevkii, 36T 0294615, 4554817, Alnus glutinosa, Fraxinus angustifolia, $6 \mathrm{~m}$, 27.07.2016.

2) Sakarya Acarlar Longozu Karamürseller Mah. Mevkii, 36T 0292915, 4554344, Quercus cerris, Fagus orientalis, Rhododendron ponticum, Carpinus betulus, Hedera helix, 47m, 27.07.2016.

3) Sakarya Üç oluk Mahallesi, 36T 290084, 4554050, Fraxinus angustifolia, Frangula dodonei, Rubus sp., Populus sp., Salix sp., 12m, 27.07.2016.

4) Sakarya Taşlıgeçit Mahallesi, Afgan Mevkii, 36T 287828, 4554679, Rubus sp., Fraxinus sp., Eryngium sp., Rumex sp., Populus sp., Mentha sp., 30m, 27.07.2016.

5) Sakarya Büyükyanık Mah. Civarı Longoz içi, 36T 0286258, 4555615; Fraxinus angustifolia, Salix alba L., Butomus sp., Alnus glutinosa, 3m, 27.07.2016.

6) Sakarya Longoz iç yolu (orta kısım), 36T 0285052, 4556834, Fraxinus sp., Salix sp., Alnus glutinosa, Salvinia natans, Fagus orientalis, Quercus sp., Carpinus betulus, Rubus sp., 6m, 27.07.2016.

7) Sakarya İşaret Mah. Mevkii, 36 T 0282924, 4554708, Carpinus betulus, Fagus orientalis, Quercus sp., Daphne pontica, Sorbus torminalis, Fraxinus angustifolia, Ruscus aculeatus, Crataegus sp., 6m, 28.07.2016.

8) Sakarya İsmet Mah. Longoz iç kesimleri, $36 \mathrm{~T}$ 0283239, 4554812, Quercus sp., Rubus sp., 
Frangula dodonei, Carpinus betulus, Fagus orientalis, Mentha pulegium, Prunella vulgaris, $7 \mathrm{~m}, 28.07 .2016$.

9) Sakarya İşaret Mah. Mevkii, 36 T 0280624 , 4555792, Populus fremontii, Carpinus betulus, Malus sylvestris, Crataegus sp., Frangula dodonei, Sorbus torminalis, Ulmus sp., Salix sp., Fraxinus sp, Mespilus sp., Smilax excelsa, 6m, 28.07.2016.

10)Sakarya Longoz Bataklık Gölü (Sazlık), $36 \mathrm{~T}$ 0281028, 4556084, Fraxinus sp., Salix sp., Carpinus sp., Populus sp., Quercus sp., Fagus orientalis., Smilax sp., Rubus sp., Crateagus sp., 5m, 28.07.2016.

11) Sakarya Ortaköy Mah. Civarı Longoz, 36T 0281000, 4556549, Lythrum sp., Typha sp., Juncus sp., Salix alba, Quercus sp., Ulmus sp., Butomus sp,, Acer sp., Juncus sp., Crataegus sp., Rubus sp., Mespilus germanica, 6m, 28.07.2016.

12) Sakarya Başoğlu Mah. Civarı, 36T 0281784, 4558166, Fagus orientalis, Quercus sp., Karışık orman altı sazlık, çayırlık alan, 43m, 28.07.2016.

13) Sakarya Dereköy Girişi Yürüyüş yolu iç kısmı, 36T 0294071, 4554842, Salix alba, Salix sp., Fraxinus angustifolia, Alnus glutinosa, Lythrum sp., Nymphaea alba, Nuphar lutea, Phragmites sp., Typha sp., Juncus sp., Sazlıklar, Fındık bahçesi, 16m, 28.07.2016.

14)Sakarya Başoğlu mahallesi, Mevkii (Bahçe kenarı orman açıklığı), 36T 0281475, 4558313, Fagus orientalis, Malus sp, Rubus sp., Rosa sp. Ruscus acueatus, Daphne pontica, Smilax excelsa, 33m, 24.03.2017.

15)Sakarya longozu orman alt1, 36T 0281731, 4558203, Quercus cerris, Quercus frainetto, Fagus orientalis, Carpinus betulus, Ruscus aculeatus, Rubus sp., Primula vulgaris subsp. sibthorpii, Viola sp., Scilla sp., Smilax excelsa, 26m, 24.03.2017.

16)Sakarya longozu orman açıklığı, 36T 0281895 , 4558445, Çayırlık alan, su birikintileri var. Juncus sp., Rubus sp., Plantago sp., Bellis perennis, Taraxaum sp., Tussilago farfara, $8 \mathrm{~m}$, 25.03.2017.

17) Sakarya Longoz sınırı, Fındık bahçesi, 36T 0282984, 4558340, Fagus orientalis, Smilax excelsa, Rubus sp., Scilla sp., 23m, 25.03.2017.

18)Sakarya longozu, 36T 0282961, 4558132, Typha sp., hakim, orman açıklığı, sazlık, bataklık, Fraxinus sp., Fagus orientalis, Carpinus betilus, Quercus sp., Alnus glutinosa, 9m, 25.03.2017.

19)Sakarya longozu, 36T 0283853, 4558215, Çayırlık-Longoz, Fraxinus sp., Quercus sp., Carpinus betilus, Crataegus sp., Rubus sp.,
Smilax excelsa, Periploca graeca, 11m, 25.03.2017.

20) Sakarya Kayık Limanı, Potbaşı Mevkii, 36T 0283988, 4558134, Longoz-Çayırlık alan, 13m, 25.03.2017.

21)Sakarya Camitepe-Körük Köyleri arası, 36T 0285554, 4557109, Longoz-Sazlık alan, Alnus glutinosa hakim, Fraxinus sp., Populus sp., Smilax sp., Typha sp., Salix sp., Periploca graeca, Rubus sp. 3m, 26.03.2017.

22) Sakarya Camitepe Köyü Mevkii, 36T 0286544, 4556806, Longoz-Sazlık alan, Alnus glutinosa, Fraxinus sp., Salix sp., Typha sp., Rubus sp., Smilax excelsa, 9m, 26.03.2017.

23) Sakarya Camitepe Köyü Güney kesimleri, 36 T0288541, 4555820, Carpinus betilus, Fagus orientalis, Quercus sp., Ruscus aculeatus, Daphne pontica, Rubus sp., Smilax excelsa, Crataegus sp., Scilla sp., Trachystemeo orientalis, $12 \mathrm{~m}, 26.03 .2017$.

24)Sakarya longoz, $36 \mathrm{~T}$ 0288555, 4555712 , Longoz-Bataklık-Sazlık alan, Fraxinus sp., Populus sp., Alnus glutinosa, Quercus sp., Smilax excelsa, Periploca graeca, Rubus sp., Typha sp., 9m, 27.03.2017.

25)Sakarya longoz, $36 \mathrm{~T}$ 0291545, 4555512, Longoz-Sazlık alan, Fraxinus sp., Salix sp., Juncus sp., Typha sp., Rubus sp., Smilax excelsa, 12m, 27.03.2017.

\subsection{Floristik liste}

BRYOPHYTA Schimp.
POLYTRICHOPSIDA Doweld
POLYTRICHALES M. Fleisch.

Polytrichaceae Schwägr.

1. Atrichum angustatum (Brid.) Bruch \& Schimp.

12. istasyon, toprak üzeri, U2514.

2. A Atrichum crispum (James) Sull. 7 ve 8. istasyon, toprak üzeri, U2468; U2469. (Türün doğruluğu Richard H. ZANDER tarafindan yapılmıştır).

3. *Atrichum tenellum (Röhl.) Bruch \& Schimp. 14. istasyon, toprak üzeri, U2777.

4. Atrichum undulatum (Hedw.) P. Beauv. 2. 3. 6. 12. ve 16. istasyon, toprak üzeri, U2466, U2465, U2513, U2467, U2465.

5. Pogonatum aloides (Hedw.) P. Beauv. 2 ve 12. istasyon, toprak üzeri, U2515, U2464.

6. Polytrichum formosum Hedw. 3. 6. ve 7. istasyon, toprak üzeri, U2516, U2517, U2470.

7. Polytrichum juniperinum Hedw. 8. istasyon, toprak üzeri, U2512. 
BRYOPSIDA Rothm.

FUNARIALES M. Fleisch.

Funariaceae Schwägr.

8. **Physcomitrium eurystomum Sendtn. 19. ve 21. toprak üzeri, U2789, U2791; 25. istasyon, kum üzeri, U2788.

9. Funaria hygrometrica Hedw.

21. istasyon, toprak üzeri, U2792; 1. istasyon, beton üzeri, U2495.

GRIMMIALES M. Fleisch.

Grimmiaceae Arn.

10. Grimmia pulvinata (Hedw.) Sm.

3. istasyon, beton üzeri, U2505.

11. Grimmia trichophylla Grev.

3. istasyon, beton üzeri, U2503; 3. istasyon, kaya üzeri, U2504.

DICRANALES H. Philib. ex M. Fleisch.

Fissidentaceae Schimp.

12. Fissidens bryoides Hedw.

2. 15. ve 21. istasyon, toprak üzeri, U2438, U2772, U2771.

13. Fissidens crassipes Wilson ex Bruch \& Schimp. 3. istasyon, toprak üzeri; U2248.

14. Fissidens taxifolius Hedw.

1. 10. 12. 16. ve 22. istasyon, toprak üzeri, U2439, U2440, U2441, U2776, U2773; 22. ve 23. istasyon, kum üzeri, U2774, U2775; 23. istasyon, kaya üzeri, U2441.

Ditrichaceae Limpr.

8. 12. istasyon, toprak üzeri, U2444, U2445.

15. *Ditrichum subulatum Hampe

8. istasyon, toprak üzeri, U2510.

16. Pleuridium acuminatum Lindb 22. istasyon, toprak üzeri, U2793.

17. Pleuridium subulatum (Hedw.) Rabenh. 8. 10. ve 17. istasyon, toprak üzeri, U2508, U2509, U2797; 15. istasyon, kök üzeri, U2795; 15. istasyon, kum üzeri, U2796.

18. $\triangle$ Pseudephemerum nitidum (Hedw.) Loeske 7. istasyon, toprak üzeri, U2511.

Dicranaceae Schimp.

19. **Dicranella rufescens (Dicks.) Schimp

1. toprak üzeri, U2786.

20. ADicranella staphylina H.Whitehouse 14. istasyon, toprak üzeri, U2783.

21. *Dicranella subulata (Hedw.) Schimp. 15. istasyon, toprak üzeri, U2787.

22. Dicranum scoparium Hedw. 18. istasyon, toprak üzeri, U2256. POTTIALES M. Fleisch.

Pottiaceae Schimp.

23. Barbula unguiculata Hedw.

21. istasyon, toprak üzeri, U2815; 23. istasyon, kum üzeri, U2817; 1 . istasyon, beton üzeri, U2518.

24. *Dialytrichia mucronata (Brid.) Broth.

5. istasyon, meşe üzeri, U2462.

25. *Didymodon sinuosus (Mitt.) Delogne
1. ve 3. istasyon, kaya üzeri, U2522, U2523.

26. *Gymnostomum calcareum Nees \& Hornsch.

3. istasyon, beton üzeri, U2520.

27. Syntrichia laevipila Brid.

1. istasyon, ağaç gövde üzeri, U2459.

28. **Syntrichia papillosa (Wilson) Jur.

14. istasyon, ağaç gövde üzeri, U2460.

29. *Syntrichia ruraliformis (Besch.) Delogne

19. istasyon, toprak üzeri, U2803.

30. *Tortella squarrosa (Brid.) Limpr. (Syn:

Pleurochaete squarrosa (Brid.) Lindb.)

19. istasyon, toprak üzeri, U2798.

31. *Tortula brevissima Schiffn.

3. istasyon, ağaç gövde üzeri, U2461.

32. Tortula muralis Hedw.

1. 3. 4. ve 23. istasyon, beton üzeri, U2457, U2519, U2458, U2802.

33. Tortula truncata (Hedw.) Mitt. (Syn: Pottia truncata (Hedw.) Müll. Hal.)

17. 18. ve 21. istasyon, toprak üzeri, U2812,

U2810, U2809; 25. istasyon, kum üzeri, U2808.

34. Trichostomum brachydontium Bruch

14. istasyon, toprak üzeri, U2804; 22. istasyon, kum üzeri, U2805.

35. *Weissia brachycarpa (Nees \& Hornsch.) Jur.

2. 3. ve 14. istasyon, toprak üzeri, U2463, U2521, U2806.

36. Weissia controversa var. controversa Hedw. 22. istasyon, toprak üzeri, U3070; 22. istasyon, kum üzeri, U2807.

\section{BRYALES Limpr.}

Bryaceae Schwägr.

37. Bryum argenteum Hedw.

21. istasyon, kum üzeri, U2770.

38. * Ptychostomum pallescens (Schleich. ex Schwägr.) J.R. Spence (Syn: Bryum pallescens Schleich. ex Schwägr.)

16. toprak üzeri, U2768.

39. Ptychostomum capillare (Hedw.) Holyoak \& N. Pedersen (Syn: Bryum capillare Hedw.)

25. istasyon, ağaç gövde üzeri, U2988.

40. *Ptychostomum imbricatulum (Müll. Hal.) Holyoak \& N. Pedersen (Syn: Bryum caespiticium Hedw.)

16. istasyon, kaya üzeri, U2766.

41.Ptychostomum pseudotriquetrum (Hedw.) J.R.Spence \& H.P.Ramsay (Syn: Bryum pseudotriquetrum (Hedw.) G. Gaertn., B. Mey. \& Scherb.)

10. istasyon, toprak üzeri, U2443; 25, istasyon, kum üzeri, U2769.

42. *Ptychostomum torquescens (Bruch \& Schimp.) Ros \& Mazimpaka (Syn: Bryum torquescens Bruch \& Schimp.)

1. istasyon, beton üzeri, U2442.

Mniaceae Schwägr.

43. Plagiomnium affine (Blandow ex Funck) T.J. Kop. 
2. ve 6. istasyon, toprak üzeri, U2452, U2491.

44. *Plagiomnium elatum (Bruch \& Schimp.)

T.J.Kop.

6. istasyon, toprak üzeri, U2493.

45. *Plagiomnium ellipticum (Brid.) T.J. Kop.

8. ve 14. istasyon, toprak üzeri, U2492, U2778.

\section{ORTHOTRICHALES Dixon}

Orthotrichaceae Arn.

46. Lewinskya affinis (Brid.) F. Lara, Garilleti \& Goffinet (Syn: Orthotrichum affine Schrad. ex Brid.)

12. 13. 16. 18. 19. 24. ve 25. istasyon, ağaç gövde üzeri, U2499, U2826; U2823, U2827, U2824, U2498.

47. * Lewinskya speciosa (Nees) F. Lara, Garilleti \& Goffinet (Syn: Orthotrichum speciosum Nees)

2. istasyon, ağaç gövde üzeri, U2435.

48. * Lewinskya striata (Hedw.) F. Lara, Garilleti \& Goffinet (Syn: Orthotrichum striatum Hedw.)

49. Orthotrichum diaphanum Brid.

1. 10. ve 25. istasyon, ağaç üzeri, 2436, U2437, U2820.

50. Orthotrichum stramineum Hornsch. ex Brid.

2. istasyon, ağaç üzeri, U2434.

10. 18. ve 19. istasyon, ağaç üzeri, U2500, U2821, U2822.

51. Orthotrichum tenellum Bruch ex Brid.

3. istasyon, ağaç gövde üzeri, U2501.

52.Pulvigera lyellii (Hook. \& Taylor) Plášek, Sawicki \& Ochyra (Syn: Orthotrichum lyellii Hook. \& Taylor)

2. istasyon, ağaç gövde üzeri, U2432.

HYPNALES (M. Fleisch.) W. R. Buck \& Vitt

Fontinalaceae Schimp.

53. Fontinalis antipyretica Hedw.

3. 5. ve 11. istasyon, dere içi kök üzeri, U2526, U2527, U2449.

54. **Fontinalis hypnoides C.Hartm.

3. istasyon, su içi kavak kök üzeri, U2528.

Amblystegiaceae G. Roth.

55. Amblystegium serpens (Hedw.) Schimp.

3. istasyon, toprak üzeri, U2450.

56. *Drepanocladus aduncus (Hedw.) Warn

6. istasyon, ağaç gövde üzeri, U2533.

57. *Hygroamblystegium varium (Hedw.) Mönk. subsp. varium (Syn: Amblystegium varium (Hedw.) Lindb.)

1. istasyon, ağaç üzeri, U2529.

3. ve 11. istasyon, ağaç gövde üzeri, U2530, $\mathrm{U} 2531$.

58. *Hygroamblystegium varium (Hedw.) Mönk. var. humile (P.Beauv.) Vanderp. \& Hedenäs (Syn: Amblystegium humile (P. Beauv.) Lindb.) 6. istasyon, ağaç üzeri, U2532.

59. *Leptodictyum riparium (Hedw.) Warnst. 24. istasyon, ağaç gövde üzeri, U2531; 14. istasyon, kum üzeri, U2529.
60. Palustriella commutata (Hedw.) Ochyra (Syn: Cratoneuron commutatum (Hedw.) G. Roth) 1. istasyon, beton üzeri, U2451.

Leucobryaceae Schimp.

61. **Campylopus subulatus Schimp. ex Milde 16. istasyon, toprak üzeri, U2790.

Leskeaceae Schimp.

62. *Leskea polycarpa Ehrh. ex Hedw.

5. istasyon, ağaç gövde üzeri, U2447.

63. *Pseudoleskeella nervosa (Brid.) Nyholm 10. istasyon, ağaç gövde üzeri, U2446.

Brachytheciaceae G. Roth.

64. Brachythecium rivulare Schimp.

9. ve 24. istasyon, toprak üzeri, U2486, U2818.

65. Brachythecium rutabulum (Hedw.)Schimp.

3. istasyon, toprak üzeri, U2487; 11. istasyon, ağaç gövde üzeri, U2543.

66. *Eurhynchiastrum pulchellum (Hedw.) Ignatov \& Huttunen (Syn: Eurhynchium pulchellum (Hedw.) Jenn.)

2. istasyon, toprak üzeri, U2489.

67. *Eurhynchium angustirete (Broth.) T.J.Kop. (Syn: Eurhynchium zetterstedtii Størmer) 16. istasyon, toprak üzeri, U2799.

68. Eurhynchium striatum (Hedw.) Schimp. 12. ve 15. istasyon, toprak üzeri, U2488, U2813.

69. *Homalothecium philippeanum (Spruce) Schimp.

5. istasyon, ağaç gövde üzeri, U2545.

70. Homalothecium sericeum (Hedw.) Schimp.

5. ve 23. istasyon, ağaç gövde üzeri, U2544, U2816.

71. Kindbergia praelonga (Hedw.) Ochyra (Syn: Eurhynchium praelongum (Hedw.) Schimp., Eurhynchium praelongum var. stokesii (Turner) Dixon)

9. ve 10. istasyon, ağaç gövde üzeri, U2548, $\mathrm{U} 2549$; 6. 7. ve 19. istasyon, toprak üzeri, U2546, U2547, U2819.

72.Microeurhynchium pumilum (Wilson) Ignatov \& Vanderp. (Syn: Eurhynchium pumilum (Wilson) Schimp., Oxyrrhynchium pumilum (Wilson) Loeske, Rhynchostegiella pumila (Wilson) E.F. Warb.)

3. istasyon, toprak üzeri, U2490.

73. Oxyrrhynchium hians (Hedw.) Loeske (Syn: Eurhynchium hians (Hedw.) Sande Lac.)

7. istasyon, toprak üzeri, U2536; 4. istasyon, beton üzeri, U2535.

74. Oxyrrhynchium schleicheri (R.Hedw.) Röll 3. istasyon, toprak üzeri, U2538.

75.Pseudoscleropodium purum (Hedw.) M. Fleisch.

5. 9. 10. ve 11. istasyon, toprak üzeri, U2541, U2480, U2542, U2481.

76. Rhynchostegiella tenella (Dicks.) Limpr. 1. istasyon, ağaç gövde üzeri, U2484.

77. Rhynchostegium murale (Hedw.) Schimp. 
3. istasyon, toprak üzeri, U2537.

78. *Scleropodium cespitans (Müll. Hal.) L.F. Koch

12. istasyon, toprak üzeri, U2485.

Hypnaceae Schimp.

79. Calliergonella cuspidata (Hedw.) Loeske

9. ve 18. istasyon, toprak üzeri, U2534, U2784;

18. istasyon, ağaç gövde üzeri, U2785.

80. Hypnum andoi A.J.E. Sm. (Syn: Hypnum cupressiforme var. mamillatum Brid.)

10. istasyon, toprak üzeri, U2476.

81.Hypnum cupressiforme Hedw. var. cupressiforme

2. 8. ve 10. istasyon, ağaç gövde üzeri, U2472, U2506, U2473; 2. istasyon, toprak üzeri, U2471; 2. 10. istasyon, çürümüş kütük üzeri, U2474, U2479.

82. Hypnum cupressiforme Hedw. var. lacunosum Brid.

15. istasyon, kütük üzeri, U2773.

83.Hypnum cupressiforme Hedw. var. resupinatum (Taylor) Schimp.

1. ve 6. istasyon, ağaç gövde üzeri, U2477, $\mathrm{U} 2507$.

84. *Platygyrium repens (Brid.) Schimp.

1. istasyon, ağaç gövde üzeri, U2478.

Pterigynandraceae Schimp.

85. Pterigynandrum filiforme Hedw.

1. istasyon, ağaç gövde üzeri, U2448.

Hylocomiaceae M. Fleisch.

86. Ctenidium molluscum (Hedw.) Mitt

2. istasyon, toprak üzeri, U2475.

Cryphaeaceae Schimp.

87. *Cryphaea heteromalla (Hedw.) D. Mohr

1. 10. 11. ve 18. istasyon, ağaç gövde üzeri, U2456, U2524, U2525, U2762.

Leucodontaceae Schimp.

88. Leucodon sciuroides (Hedw.) Schwägr.

2. 6. ve 23. istasyon, ağaç gövde üzeri, U2455, U2494, U2767.

Neckeraceae Schimp.

89. Alleniella complanata (Hedw.) S. Olsson, Enroth \& D.Quandt (Syn: Neckera complanata (Hedw.) Huebener)

5. 6. 11. ve 14. istasyon, ağaç gövde üzeri, U2496, U2454, U2497; 3. istasyon, kaya üzeri, U2453; 14. kütük üzeri, U2764.

Lembophyllaceae Broth.

90.Isothecium alopecuroides (Lam. ex Dubois) Isov.

2. ve 6. istasyon, ağaç gövde üzeri, U2482, $\mathrm{U} 2539$.

91.**Isothecium myosuroides Brid. var. brachythecioides (Dixon) Braithw.

6. istasyon, ağaç gövde üzeri, U2483.

Anomodontaceae Kindb.

92. Anomodon viticulosus (Hedw.) Hook. \& Taylor
5. istasyon, ağaç gövde üzeri, U2502.

93.Pseudanomodon attenuatus (Hedw.) Ignatov \& Fedosov (Syn: Anomodon attenuatus (Hedw.) Huebener)

18. istasyon, ağaç gövde üzeri, U2779.

\section{Tartışma ve Sonuç}

Sakarya ili sınırları içerisinde yer alan Acarlar Gölü Longoz Ormanında yapılan çalışmada, 25 istasyondan toplanan 248 karayosunu örneğinin teşhis edilmesi sonucunda; 23 familya ve 58 cinse ait 93 karayosunu taksonu tespit edilmiştir. Bu taksonlardan 29 tanesi Sakarya ili briyofit florası için, 6 takson ise A2 karesi için yeni kayıtır.

Araştırma alanında bulunan türlerin familyalara göre dağılımı Tablo 1'de verilmiştir. Tespit edilen taksonların Türkiye'deki diğer bazı önemli longoz ormanları ile kıyaslanması ise Tablo 2'de verilmiştir.

Tablo 1. Araştırma alanında bulunan karayosunlarının familyalara göre dağılımı

\begin{tabular}{|l|c|c|}
\hline \multicolumn{1}{|c|}{ Familya } & $\begin{array}{c}\text { Familyalara } \\
\text { ait takson } \\
\text { sayıları }\end{array}$ & $\begin{array}{c}\text { Toplam } \\
\text { takson } \\
\text { sayısına } \\
\text { oranı (\%) }\end{array}$ \\
\hline Brachytheciaceae & 15 & 16,2 \\
\hline Pottiaceae & 14 & 15,2 \\
\hline Polytrichaceae & 7 & 7,6 \\
\hline Orthotrichaceae & 7 & 7,6 \\
\hline Amblystegiaceae & 6 & 6,4 \\
\hline Hypnaceae & 6 & 6,4 \\
\hline Bryaceae & 6 & 6,4 \\
\hline Ditrichaceae & 4 & 4,3 \\
\hline Dicranaceae & 4 & 4,3 \\
\hline Mniaceae & 3 & 3,2 \\
\hline Fissidentaceae & 3 & 3,2 \\
\hline Funariaceae & 2 & 2,1 \\
\hline Grimmiaceae & 2 & 2,1 \\
\hline Leskeaceae & 2 & 2,1 \\
\hline Lembophyllaceae & 2 & 2,1 \\
\hline Fontinalaceae & 2 & 2,1 \\
\hline Anomodontaceae & 2 & 2,1 \\
\hline Neckeraceae & 1 & 1,1 \\
\hline Leucobryaceae & 1 & 1,1 \\
\hline Leucodontaceae & 1 & 1,1 \\
\hline Pterigynandraceae & 1 & 1,1 \\
\hline Hylocomiaceae & 1 & 1,1 \\
\hline Cryphaeaceae & 1 & 1,1 \\
\hline TOPLAM & $\mathbf{9 3}$ & $\mathbf{1 0 0}$ \\
\hline
\end{tabular}


$\mathrm{Bu}$ dağılımlara bakıldığında içerdiği takson sayısı en yüksek familyalar sırası ile Brachytheciaceae (15), Pottiaceae (14), Polytrichaceae ve Orthotrichaceae (7), Amblystegiaceae, Hypnaceae ve Bryaceae (6)'dir. Bunlar1; Ditrichaceae ve Dicranaceae (4), Mniaceae ve Fissidentaceae (3),

Gerek A1 ve A2 karesi kontrol listelerinde (Ursavaş ve Abay, 2009; Ursavaş ve ark, 2009), gerekse Türkiye briyofit check listelerinde (Uyar ve Çetin 2004; Kürschner ve Erdağ, 2005) Pottiaceae ve Brachytheciacea familyaları, içerdiği takson sayısı
Funariaceae, Grimmiaceae, Leskeaceae, Lembophyllaceae, Fontinalaceae ve Anomodontaceae (2), ve bir (1) taksonla; Neckeraceae, Leucobryaceae, Leucodontaceae, Pterigynandraceae, Hylocomiaceae ve Cryphaeaceae familyaları takip etmektedir. açısından en büyük familyalardır. Bunun nedeni bu familyaya ait taksonların farklı ortam koşullarına göre çok iyi adapte olabilen taksonlar olmasıdır. Oldukça nemli olan longoz ormanlarına da uyum sağlamış taksonların bu familyalarda da öne çıktığı görülmektedir.

Tablo 2. Araştırma alanlarından tespit edilen taksonların Türkiye'deki diğer bazı önemli longoz ormanlarında yapılmış olan çalışmalar ile kıyaslanması

\begin{tabular}{|c|c|c|c|c|c|c|}
\hline \multirow[t]{2}{*}{ Familyalar } & \multicolumn{2}{|c|}{$\begin{array}{c}\text { İğneada Milli Parkı } \\
\text { Longoz Ormanları } \\
\text { (Kırklareli) } \\
\text { (Işın ve Ursavaş, } \\
\text { 2018) }\end{array}$} & \multicolumn{2}{|c|}{$\begin{array}{c}\text { Acarlar Gölü } \\
\text { Longoz Ormanları } \\
\text { (Sakarya) }\end{array}$} & \multicolumn{2}{|c|}{$\begin{array}{c}\text { Kocaçay Deltası Longoz } \\
\text { Ormanları (Bursa) } \\
\text { (Ursavaş ve Keçeli, } \\
\text { 2019) }\end{array}$} \\
\hline & $\begin{array}{c}\text { Takson } \\
\text { sayısı }\end{array}$ & $\%$ & $\begin{array}{c}\text { Takson } \\
\text { sayısı }\end{array}$ & $\%$ & $\begin{array}{c}\text { Takson } \\
\text { sayısı }\end{array}$ & $\%$ \\
\hline Pottiaceae & 20 & 19,0 & 14 & 15,3 & 26 & 23,2 \\
\hline Brachytheciaceae & 14 & 13,3 & 15 & 16,3 & 15 & 13,4 \\
\hline Polytrichaceae & 9 & 8,6 & 7 & 7,6 & 5 & 4,5 \\
\hline Orthotrichaceae & 8 & 7,7 & 7 & 7,6 & 6 & 5,2 \\
\hline Hypnaceae & 6 & 5,8 & 5 & 5,4 & 8 & 7,1 \\
\hline Bryaceae & 5 & 4,9 & 5 & 5,4 & 10 & 8,9 \\
\hline Funariaceae & 4 & 3,8 & 2 & 2,2 & 1 & 0,9 \\
\hline Grimmiaceae & 4 & 3,8 & 2 & 2,2 & 4 & 3,6 \\
\hline Fissidentaceae & 4 & 3,8 & 2 & 2,2 & 4 & 3,6 \\
\hline Mniaceae & 4 & 3,8 & 3 & 3,2 & 4 & 3,6 \\
\hline Ditrichaceae & 3 & 2,9 & 5 & 5,4 & 4 & 3,6 \\
\hline Bartramiaceae & 3 & 2,9 & - & - & - & - \\
\hline Amblystegiaceae & 3 & 2,9 & 6 & 6,5 & 3 & 2,6 \\
\hline Dicranaceae & 2 & 1,9 & 4 & 4,1 & 4 & 3,6 \\
\hline Leskeaceae & 2 & 1,9 & 2 & 2,2 & 2 & 1,8 \\
\hline Plagiotheciaceae & 2 & 1,9 & - & - & 2 & 1,8 \\
\hline Leucodontaceae & 2 & 1,9 & 1 & 1,1 & 2 & 1,8 \\
\hline Neckeraceae & 2 & 1,9 & 1 & 1,1 & 4 & 3,6 \\
\hline Anomodontaceae & 2 & 1,9 & 2 & 2,2 & 1 & 0,9 \\
\hline Fontinalacea & 1 & 0,9 & 2 & 2,2 & - & - \\
\hline Leucobryaceae & 1 & 0,9 & 1 & 1,1 & 1 & 0,9 \\
\hline Pseudoleskeaceae & 1 & 0,9 & - & - & - & - \\
\hline Plasiadelphaceae & 1 & 0,9 & 1 & 1,1 & - & - \\
\hline Cryphaeaceae & 1 & 0,9 & 1 & 1,1 & 1 & 0,9 \\
\hline Lembophyllaceae & 1 & 0,9 & 2 & 2,2 & 2 & 1,8 \\
\hline Rhabdoweissiaceae & - & - & - & - & 1 & 0,9 \\
\hline Pterigynandraceae & - & - & 1 & 1,1 & - & - \\
\hline Hylocomiaceae & - & - & 1 & 1,1 & 1 & 0,9 \\
\hline Leptodontaceae & - & - & - & - & 1 & 0,9 \\
\hline TOPLAM & 105 & & 93 & & 112 & \\
\hline
\end{tabular}


Tablo 2 incelendiğinde; içerdiği takson sayısı fazla olan bir diğer familya ise; Bryaceae üyeleridir. Özellikle, Kocaçay Deltası Longoz Ormanlarında 10 takson gibi oldukça yüksek bir oranda temsil edilmektedir. Kumlu toprak üzerlerinde, orman örtüsü altında veya açıklık alanlarda bilhassa akarsu ve gölet kenarlarında yayılış gösteren bu familya üyeleri, yağışlı ve kurak iklimlerde adapte olabilmiş bireyler içermektedirler.

Araştırma alanları içerisinde en fazla karayosunu taksonu 112 taksonla Kocaçay Deltası Longoz Ormanlar'ından verilmiştir. Her üç araştırma alanında da ilk iki sırayı Pottiaceae ve Brachytheciaceae familyaları almaktadır. Batramiaceae ve Pseudoleskeaceae familyalarına ait taksonlar sadece İğneada Longoz Ormanları Milli Parkından kaydı verilirken; Rhabdoweissiaceae ve Leptodontaceae familyalarına ait taksonlar sadece Bursa Karacabey Longoz Ormanları'ndan verilmiştir. Ayrıca; Pterigynandraceae familyasına ait taksonların ise sadece Acarlar Gölü Longoz Ormanlar'ından kaydının verildiği görülmektedir.

İnsan faaliyetlerinin ulaşabildiği birçok alanda olduğu gibi Acarlar Gölü Longozu'nun bulunduğu sahada da bitki örtüsünün bugünkü görünümünü almasında beşeri faktörler önemli bir rol oynamaktadır. Gerçekten, bir sahanın bitki örtüsünü belirleyen unsurlar, iklim, toprak ve yüzey şekilleri gibi doğal süreçler olsa da Acarlar Gölü Longozu'nda olduğu gibi hassas alanlarda, insan faaliyetleri doğal gelişimi kısıtlayan, hatta tersine çevirerek tahrip eden uygulamaları gerçekleştirmektedir. $\mathrm{Bu}$ koşullar altında saha, iklim ve diğer fiziki unsurlar açısında gür bir bitki örtüsü sahip olma potansiyeli varken, yanlış uygulamalar ve tahribat nedeniyle karakter değişikliğine maruz kalmıştır. Buna göre doğal bitki örtüsü birçok noktada yerini çalı topluluklarına ve tarım alanlarına terk etmiştir (Gönençgil, 2008).

Tüm tahribata rağmen insanın ulaşamadığı longozun içinde yer alan gölde hem orman örtüsü hem de orman altı florası çok zengindir. Göl ortamına bağlı olarak bu alanlar henüz tam anlamıyla tahribata uğramamıştır. Ancak daha önceki uygulamalarla kurutulan ve tüm longoz alanının yaklaşık \%40'ına karşılık gelen sahalarda bugün başta findık ve mısır olmak üzere tarım ürünlerine ait bitkiler yer almaktadır (Gönençgil, 2008).

Acarlar Gölü Longoz Ormanları sınırları içerisinde ülkemiz briyofit florasına kazandırılan üç karayosunu bulunmaktadır (Şekil 6.8). Bu türler; Atrichum crispum, Pseudephemerum nitidum ve
Dicranella staphylina'dır. Pseudephemerum aynı zamanda Türkiye briyofit florası için yeni bir cins kaydı olması bakımından da önemlidir (Ursavaş ve Işın, 2019; Ursavaş ve ark., 2020). Atrichum crispum ve Pseudephemerum nitidum'un Büyük yanık mahallesi yakınlarında özellikle tarım yapılan alanlara yakın bir yerden kaydı verilmiştir (Şekil 1). $\mathrm{Bu}$ alandaki tarımsal faaliyetlerden olumsuz şekilde etkilenmeleri muhtemeldir. Dicranella staphylina'nın da Başoğlu mahellesi yakınlarında kaydı verilmiştir. $\mathrm{Bu}$ alandaki yapılaşmanın (yol, ev, yazlık, baraka, boru hattı vb.) bu türün varlığını ileriki zamanlarda tehlikeye sokacağını düşündürmektedir.

\section{Teșekkür}

$\mathrm{Bu}$ çalışma, TÜBİTAK tarafindan $115 \mathrm{Z364}$ Numaralı proje ile desteklenmiştir.

\section{Kaynaklar}

Alataş M. Batan N. Ezer T. 2019. The Epiphytic Bryophyte Communities of Kamilet Valley (Artvin/Turkey). Turkish Journal of Botany. 43:4, 551-569.

Alataş M. Uyar G. Ezer T. Ören M. 2019a. The Epiphytic Bryophyte Communities of Akyazı District (Sakarya, Turkey): A Multivariate Study of Community-Habitat Relationships. Anatolian Bryology. 5:2, 8599.

Baykal M.H. 2006. Acarlar Longozu (Sakarya) Örneğinde Korunan Alanlarda Eğitim ve Bilinçlendirme Araçlarının Genel Özelliklerinin Saptanması. Ankara Üniversitesi, Fen Bilimleri Enstitüsü. Yüksek Lisans Tezi.

Can Gözcü M. Uyar G. Alataş M. Ezer T. Ören M. 2018. Epiphytic bryophyte vegetation of the Samanli Mountains (Sakarya-KocaeliYalova-Bursa) in Northwest Turkey. Botanica Serbica. 42:2, 157-171.

Can Gözcü M. Uyar G. Alataş M. Ezer T. Ören M. 2019. The Bryophyte Flora of The Samanli Mountains (Sakarya, Kocaeli, Yalova, Bursa) In North-West Turkey. Arctoa. 28:1, 58-74.

Ezer T. 2017. Contributions to the bryophyte flora of Turkey. Acta Biologica Turcica. 30:4, 128-133.

Gönençgil B. 2008. Tehdit Altındaki Kıyı Alanlarına Bir Örnek: Acarlar LongozuKarasu, Sakarya, Ankara Üniversitesi Türkiye Coğrafyası Araştırma ve Uygulama Merkezi (TÜCAUM). V. Ulusal Coğrafya Sempozyumu. Ankara. pp. 31-38.

Greven H.C. 2003. Grimmias of The World. Leiden: Backhuys Publishers. Leiden. 
Henderson D.M. 1961. Contributions to the Bryophyte Flora of Turkey: IV. Notes from the Royal Botanic Garden Edinburgh. 23, 263-278.

Heyn C.C. Bernstadt I. 2004. The Bryophyte Flora of Israel and Adjacent Regions. The Israel Academy of Sciences and Humanities, Jerusalem.

Hodgetts N. Lockhart N. 2020. Checklist and country status of European bryophytes update 2020. Irish Wildlife Manuals, No. 123. National Parks and Wildlife Service, Department of Culture, Heritage and the Gaeltacht, Ireland.

Işıın Z. Ursavaş S. 2018. The Moss Flora of İğneada Floodplain Forests National Park (Demirköy, Kırklareli) Turkey. Anatolian Bryology. 4:2, 92-106.

Kavgaci A. Özalp G. Özhayat N. 2007. Flora of Igneada Fioodplain Forests (Longozes) and Their Surroundings. JFFIU. 57, 60-89.

Kürschner H. Erdağ A. 2005. Bryophytes of Turkey: An annotatedreference list of the species with synonyms from the recentliterature, and an annotated list of Turkish bryological literature. Turk J. Bot. 29, 95-154.

Cortini P.C. 2001. Flora dei muschi d'Italia (Sphagnopsida, Andreaeopsida, Bryopsida. I parte). Antonio Delfino Editore Press. Roma.

Cortini P.C. 2006. Flora dei muschi d'Italia (Sphagnopsida,

Andreaeopsida, Bryopsida.II parte). Antonio Delfino Editore Press. Roma.

Sarığlu S. Keçeli T. 2018. Contributions to the Liverwort (Marchantiophyta) Flora of Acarlar Lake Floodplain Forest (Sakarya). Anatolian Bryology. 4:2, 107-121.

Schuck A. Parviainen J. Bücking W. 1994. A review of approaches to forestry research on structure, succession and biodiversity of a disturbed and semi-natural forests and woodland in Europe. European Forest Institute Working Paper 3. Joensuu.

Smith A.J.E. 1980. The Moss Flora of Britain and Ireland. Cambridge University Press. Cambridge.

Smith A.J.E. 2004. The Moss Flora of Britain and Ireland (Second Edition). Cambridge University Press. London.

URL1. Demirköy 2006. Web sitesi: http://demirkoy1.sitemynet.com/Doga.ht m, [Erişim: 9 Temmuz 2006.]

Ursavaş S. Abay G. 2009. Türkiye'nin A2 Karesinin Karayosunları (Musci) Kontrol Listesi. Bartın Orman Fakültesi Dergisi. 11:16, 33-43.
Ursavaş S. Keçeli T. 2019. The Moss Flora of Kocaçay Delta (Karacabey-Bursa) Floodplain Forests in Turkey. Anatolian Bryology. 5:1, 22-34.

Ursavaş S. Işın Z. 2019. New records of Bryum gemmiferum and Atrichum crispum for Turkey. Plant Biosystems. 153:5, 686-690.

Ursavaş S. Keçeli T. Uyar G. Ören M. 2020. Dicranella staphylina (Dicranaceae), a new moss record from Turkey and South West Asia. Plant Biosystems. https://doi.org/10.1080/11263504.2020.176 $\underline{2778}$.

Ursavaş S. Şahin A. Abay G. 2009. Türkiye'nin A1 karesinin karayosunları (Musci) kontrol listesi. I. Ulusal Batı Karadeniz Ormancılık Kongresi Bildiriler Kitabı. Özel sayı. 2, 604612.

Uyar G. Çetin B. 2004. A new check-list of the mosses of Turkey Journal of Bryology. 26, 203-220.

Wenger E. Zinke A. Gutzweiler K.A. 1990. Present Situation of the European Floodplain Forests. For Ecology and Management. 33:34, 5-12. 